\title{
Amberlite XAD-2 impregnated Cyanex272: sorption desorption studies of thorium(IV)
}

\author{
By M. Karve* and J. V. Gholave \\ Department of Chemistry, University of Mumbai, Vidyanagari, Mumbai - 400 098, India
}

(Received November 24, 2009; accepted in final form November 11, 2010)

\section{Amberlite XAD-2 / Cyanex272 / Th(IV) / Monazite sand}

\begin{abstract}
Summary. Amberlite XAD-2 impregnated with Cyanex 272 was packed in a column and studied for separation and recovery of Th(IV). The effect of various parameters influencing sorption of Th(IV) viz. acid concentration, aqueous phase flow rates, nature and concentration of eluents and other ions were systematically studied. Under optimized conditions $\mathrm{Th}(\mathrm{IV})$ was quantitatively sorbed from $0.001 \mathrm{M} \mathrm{HNO}_{3}$ and recovered using $10 \mathrm{~cm}^{3}$ of $4.0 \mathrm{M} \mathrm{HCl}$ at $0.6 \mathrm{~cm}^{3} \mathrm{~min}^{-1}$ flow rate. Batch studies using impregnated resin were evaluated for using Langmuir and Freundlich adsorption isotherms. The sorption capacity of the impregnated resin for Th(IV) was $8.48 \mathrm{mmol} \mathrm{g}^{-1}$. The limit of detection for $\mathrm{Th}(\mathrm{IV})$ was $0.67 \mu \mathrm{g} \mathrm{dm}^{-3}$ and a reusability for more than 65 cycles was observed. The method developed was applied for isolation of Th(IV) from monazite sand. It was reproducible with a relative standard deviation (R.S.D.) of $0.8 \%$.
\end{abstract}

\section{Introduction}

Solvent extraction has been commonly used for separation and determination of thorium owing to its industrial importance. However, solid phase extraction has emerged as an alternative to liquid-liquid extraction as it minimizes the large scale use of organic solvents and thus reduces the wastes and the problems associated with their disposal. Solid polymeric resin based specific ion collectors have made significant contribution for the detection of trace elements and several methods for preconcentration and determination of thorium exist [1]. Amberlite XAD series resins [2-7], Merrifield's chloromethylated resin [8], and silica gel [9] were chemically modified for separation and determination of thorium from soil, sediment $[3,8]$, and nuclear spent fuel sample $[6,7]$. Solid phase extraction methodologies involving impregnation based upon physical interaction of a ligand on a solid support is a simple and easy process [10-16] and avoids the complexities involved in the chemical reaction for synthesis of ligand $[5,7,8]$ and/or its binding to the solid support $[2-7,9]$. Impregnating a liquid extractant on a solid support for recovery of valuable metals is

*Author for correspondence

(E-mail: mkarve@yahoo.com, manjusha@chem.mu.ac.in). interesting $[14,15]$ as it not only combines the high distribution coefficients amenable with liquid extractants but also the multistage characteristic of chromatographic process. High sorption capacity and good enrichment factor was reported using Amberlite XAD-2 impregnated with Cyanex302 \{bis(2,4,4-trimethylpentyl)monothiophosphinic acid \} [15]. In the present work, XAD-2 was impregnated with Cyanex 272 \{bis(2,4,4-trimethylpentyl)phosphinic acid to understand the sorption desorption characteristics of $\mathrm{Th}(\mathrm{IV})$ and facilitate its recovery from associated elements and monazite sand. Amberlite XAD-2 was selected as a solid support due to its characteristic physical properties, good mechanical stability, and structural rigidity (mean pore diameter $90 \AA$, 20-60 mesh, and average surface area $\left.330 \mathrm{~m}^{2} \mathrm{~g}^{-1}\right)$. The sorption desorption conditions were optimized by a column method, while a batch mode was used to study Langmuir and Freundlich adsorption isotherms.

\section{Experimental}

\subsection{Instrumentation}

A glass column of $150 \mathrm{~mm}$ length and $10 \mathrm{~mm}$ internal diameter was used for the packing of the solid phase. A wrist action flask shaker EXPO from General Trading Corporation, India was used for equilibration in batch method. Digispec-110D visible spectrophotometer was used for metal detection. A flame atomic absorption spectrophotometer (FAAS), AAnalyst200 (Perkin Elmer) and an inductively coupled plasma atomic emission spectrometer (ICP-AES), JY JOBIN YVON HORIBA ULTIMA 2 were also used.

\subsection{Chemicals and reagents}

A stock solution containing $2.5 \mathrm{mg} \mathrm{cm}^{-3} \mathrm{Th}(\mathrm{IV})$ was prepared from $\mathrm{Th}\left(\mathrm{SO}_{4}\right)_{2} \cdot 9 \mathrm{H}_{2} \mathrm{O}$ (Loba Chemie). It was standardized complexometrically [16] and a working solution containing $20 \mu \mathrm{g} \mathrm{cm}^{-3}$ of Th(IV) was prepared by appropriate dilution. An aqueous solution of Arsenazo(III) $(0.1 \% \mathrm{w} / \mathrm{v})$ (S.d. Fine Chemicals) was used for spectrophotometric determination of Th(IV). Amberlite XAD-2 was purchased from Supelco, Sigma Aldrich Co. Cyanex272 was obtained as a gift sample from Cytec Canada. All chemicals and reagents used were of A.R. grade. 


\subsection{Preparation of Cyanex272 impregnated Amberlite XAD-2 resin}

Amberlite XAD-2 resin (100 mg) and Cyanex272 (100 mg) in $10 \mathrm{~cm}^{3}$ methanol were mixed together till it resulted in almost complete evaporation of methanol and was then kept overnight at room temperature. The impregnated resin was uniformly packed in a glass column $(150 \mathrm{~mm}$ length and $10 \mathrm{~mm}$ internal diameter) with glass wool as support.

\subsection{General procedure for sorption of $\mathrm{Th}(\mathrm{IV})$}

The column was preconditioned with 10 bed volumes of $0.001 \mathrm{M} \mathrm{HNO}_{3}$. A $10.0 \mathrm{~cm}^{3}$ sample solution containing $2.0 \mu \mathrm{g} \mathrm{cm}^{-3} \mathrm{Th}(\mathrm{IV})$ in $0.001 \mathrm{M} \mathrm{HNO}_{3}$ was sorbed on the column at a flow rate of $1.0 \mathrm{~cm}^{3} \mathrm{~min}^{-1}$ and then recovered with $10.0 \mathrm{~cm}^{3}$ of $4.0 \mathrm{M} \mathrm{HCl}$ at a flow rate of $0.6 \mathrm{~cm}^{3} \mathrm{~min}^{-1}$. $\mathrm{Th}(\mathrm{IV})$ was determined spectrophotometrically using $0.1 \%$ Arsenazo(III) at $660 \mathrm{~nm}$ [17].

\subsection{Procedure for the analysis of monazite sand}

A $0.1 \mathrm{~g}$ sample of monazite sand was digested in concentrated $\mathrm{H}_{2} \mathrm{SO}_{4}$ at $250{ }^{\circ} \mathrm{C}$ [18] and after repeated extraction with $1: 10 \mathrm{H}_{2} \mathrm{SO}_{4}$ was finally diluted to a suitable volume. A known aliquot of sample was passed through the column as per general procedure.

\section{Results and discussion}

\subsection{Column mode}

Optimization for preconcentration and recovery of Th(IV)

\section{Influence of amount of Cyanex272}

Amberlite XAD-2 (100 mg) was impregnated with varying amounts of Cyanex272 (25-100 mg) to study sorption of $\mathrm{Th}(\mathrm{IV})$. Using Th(IV) $(20 \mu \mathrm{g})$ in $0.001 \mathrm{M} \mathrm{HNO}_{3}$ and passing through the column packed with different amounts of Cyanex272 at $1.0 \mathrm{~cm}^{3} \mathrm{~min}^{-1}$ flow rate indicated that $100 \mathrm{mg}$ of Cyanex272 was necessary to achieve quantitative sorption $(99.3 \pm 0.8) \%$ of $\mathrm{Th}(\mathrm{IV})$. Lower sorption of Th(IV) using Cyanex 272 less than $100 \mathrm{mg}$ for impregnation is possibly due to incomplete pore filling of the resin and thus reducing the accessibility for complexation of Th(IV).

\section{Effect of aqueous phase acidity and flow rate}

Sorption of Th(IV) was studied at different aqueous phase acidities (Fig. 1). Th(IV) sorption was quantitative from $0.001 \mathrm{M} \mathrm{HNO}_{3}$ and $0.001 \mathrm{M} \mathrm{HCl}$, presumably due to sorption on Cyanex272 as a cationic species. Further studies were carried out using $0.001 \mathrm{M} \mathrm{HNO}_{3}$ as the aqueous phase. Aqueous phase flow rate was optimized by passing a sample solution $\left(10.0 \mathrm{~cm}^{3}\right)$ containing $2.0 \mu \mathrm{g} \mathrm{cm}^{-3} \mathrm{Th}(\mathrm{IV})$ in $0.001 \mathrm{M} \mathrm{HNO}_{3}$ through the column at $(0.5-5.0) \mathrm{cm}^{3} \mathrm{~min}^{-1}$ flow rate. Sorption of Th(IV) was quantitative with a flow rate of $1.0 \mathrm{~cm}^{3} \mathrm{~min}^{-1}$. While it was $(98.7 \pm 0.2) \%$ and $(96.3 \pm 0.2) \%$, using sample flow rates $2.0 \mathrm{~cm}^{3} \mathrm{~min}^{-1}$ and $5.0 \mathrm{~cm}^{3} \mathrm{~min}^{-1}$ respectively due to its insufficient contact with the impregnated resin. Thus, a flow rate of $1.0 \mathrm{~cm}^{3} \mathrm{~min}^{-1}$ was used in all studies.

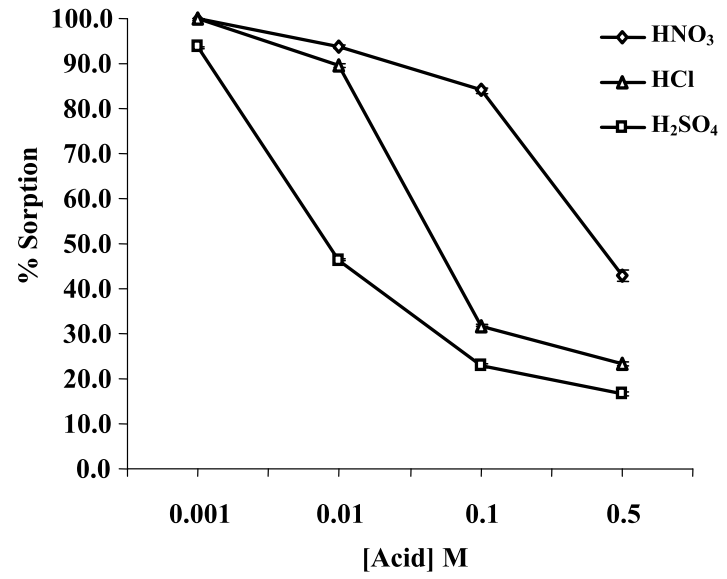

Fig. 1. Effect of aqueous phase acidity on sorption of Th(IV). Experimental condition: column packed with $100 \mathrm{mg}$ Amberlite XAD-2 impregnated with $100 \mathrm{mg}$ Cyanex 272 . Aqueous phase condition = $20 \mu \mathrm{g} \mathrm{Th}(\mathrm{IV})$ in $10.0 \mathrm{~cm}^{3}$, at $1.0 \mathrm{~cm}^{3} \mathrm{~min}^{-1}$ flow rate.

\section{Breakthrough volume}

Different sample volumes $(10-1000) \mathrm{cm}^{3}$ containing $20 \mu \mathrm{g}$ Th(IV) were passed through the column packed with the impregnated resin at the optimum flow rate. Using these sample solutions not more than $0.006 \pm 0.006 \mu \mathrm{g} \mathrm{cm}^{-3} \mathrm{Th}(\mathrm{IV})$ was detected in the aqueous solution upto $1000 \mathrm{~cm}^{3}$. Therefore, the preconcentration factor of 100 was achieved by using $10.0 \mathrm{~cm}^{3}$ of $4.0 \mathrm{M} \mathrm{HCl}$ as eluting agent.

\section{Influence of various eluting agents on desorption of $\operatorname{Th}(\mathrm{IV})$}

Recovery of Th(IV) was studied using different eluents (Table 1). Higher concentrations of $\mathrm{HNO}_{3}$ and $\mathrm{H}_{2} \mathrm{SO}_{4}$ were not studied as preliminary experiments indicated leaching of the extractant from the impregnated resin. Recovery of $\mathrm{Th}(\mathrm{IV})$ was quantitative $(99.3 \pm 0.8) \%$ with $4.0 \mathrm{M}$ $\mathrm{HCl}$ and $2.0 \mathrm{M} \mathrm{H}_{2} \mathrm{SO}_{4}$. However, $4.0 \mathrm{M} \mathrm{HCl}$ was selected as an eluent. Different volumes $(5.0-20.0) \mathrm{cm}^{3}$ and flow rates $(0.2-1.0) \mathrm{cm}^{3} \mathrm{~min}^{-1}$ of $4.0 \mathrm{M} \mathrm{HCl}$ were studied. Using $5.0 \mathrm{~cm}^{3}$ of $\mathrm{HCl}$ at flow rate $0.6 \mathrm{~cm}^{3} \mathrm{~min}^{-1}$, Th(IV) recovery was $91.5 \pm 0.3 \%$ and with $10.0 \mathrm{~cm}^{3}$ of $4.0 \mathrm{M} \mathrm{HCl}$ at $0.8 \mathrm{~cm}^{3} \mathrm{~min}^{-1}$ flow rate its recovery was of $97.3 \pm 0.2 \%$. Eluent selected for further studies was $10.0 \mathrm{~cm}^{3}, 4.0 \mathrm{M} \mathrm{HCl}$ at $0.6 \mathrm{~cm}^{3} \mathrm{~min}^{-1}$ flow rate.

\section{Column bed reusability}

The stability and potential reusability of the column was assessed by monitoring the sorption of Th(IV) through a number of sorption desorption cycles under the optimum conditions. The sorption of Th(IV) was $(99.8 \pm 0.3) \%$ and it remained unchanged even after continuous usage upto 65 cycles (Fig. 2) indicating a very high reusability and reliability of the resin.

\section{Effect of diverse ions on sorption of Th(IV)}

The influence of alkali, alkaline earths, transition metals and rare earth elements on the sorption of Th(IV) was studied under its optimum conditions. The tolerance limit was set as the amount of foreign ion required to cause $\pm 2.0 \%$ 
Table 1. Influence of eluting agents (aqueous phase condition $=20 \mu \mathrm{g} \mathrm{Th}(\mathrm{IV})$ in $10.0 \mathrm{~cm}^{3}$ of $0.001 \mathrm{M}$ $\mathrm{HNO}_{3}$, at $1.0 \mathrm{~cm}^{3} \mathrm{~min}^{-1}$ flow rate, elution condition $=10.0 \mathrm{~cm}^{3}$, at $0.6 \mathrm{~cm}^{3} \mathrm{~min}^{-1}$ flow rate).

\begin{tabular}{lrcccccc}
\hline $\begin{array}{l}\text { Conc. }[\mathrm{M}] \rightarrow \\
\text { Eluents } \downarrow\end{array}$ & \multicolumn{1}{c}{0.01} & 0.1 & 0.5 & \multicolumn{1}{c}{$\begin{array}{c}1.0 \\
\text { \% Recovery }\end{array}$} \\
\hline $\mathrm{HCl}$ & & & \multicolumn{2}{c}{2.0} & 3.0 & 4.0 \\
$\mathrm{HNO}_{3}$ & $9.4 \pm 0.2$ & $23.8 \pm 0.5$ & $50.4 \pm 0.3$ & $73.9 \pm 0.2$ & - & - & - \\
$\mathrm{H}_{2} \mathrm{SO}_{4}$ & $47.6 \pm 0.3$ & $72.2 \pm 0.2$ & $90.9 \pm 0.2$ & $96.3 \pm 0.3$ & $99.2 \pm 0.3$ & - & - \\
$\mathrm{HClO}_{4}$ & $7.2 \pm 0.2$ & $38.7 \pm 0.4$ & $67.6 \pm 0.6$ & $78.1 \pm 0.2$ & $88.0 \pm 0.3$ & $89.4 \pm 0.2$ & $92.9 \pm 0.5$ \\
$\mathrm{CH}_{3} \mathrm{COOH}$ & $1.4 \pm 0.2$ & $3.3 \pm 0.2$ & $7.7 \pm 0.3$ & $18.0 \pm 0.6$ & $27.9 \pm 0.7$ & $35.6 \pm 0.4$ & $44.4 \pm 0.3$ \\
$\mathrm{H}_{2} \mathrm{C}_{2} \mathrm{O}_{4}$ & $60.3 \pm 0.3$ & $81.9 \pm 0.4$ & $87.5 \pm 0.5$ & $92.8 \pm 0.3$ & - & - & - \\
$\left(\mathrm{NH}_{4}\right)_{2} \mathrm{CO}_{3}$ & $3.4 \pm 0.2$ & $15.9 \pm 0.5$ & $63.4 \pm 0.2$ & $56.8 \pm 0.4$ & - & - & - \\
\hline
\end{tabular}

$\mathrm{a}=\%$ R.S.D. $(N=3)$.

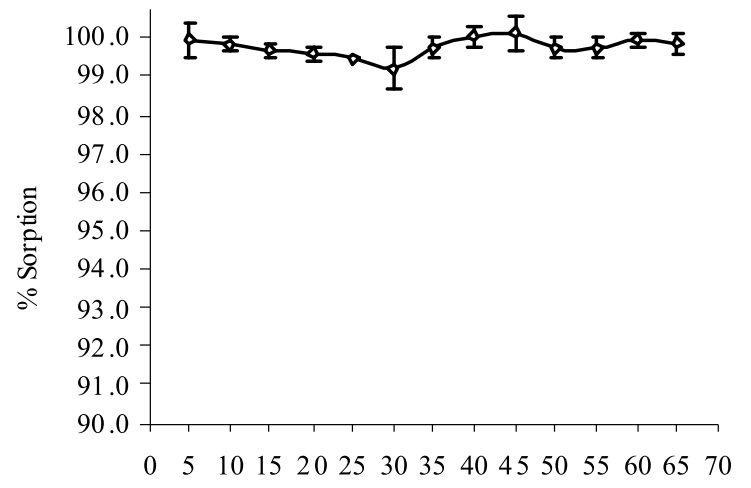

No. of cycles

Fig. 2. Column bed reusability. Experimental condition: column packed with $100 \mathrm{mg}$ Amberlite XAD-2 impregnated with $100 \mathrm{mg}$ Cyanex272. Aqueous phase condition $=20 \mu \mathrm{g} T \mathrm{Th}(\mathrm{IV})$ in $10.0 \mathrm{~cm}^{3}$ of $0.001 \mathrm{M} \mathrm{HNO}_{3}$, at $1.0 \mathrm{~cm}^{3} \mathrm{~min}^{-1}$ flow rate. Elution condition $=$ $10.0 \mathrm{~cm}^{3}$ of $4.0 \mathrm{M} \mathrm{HCl}$, at $0.6 \mathrm{~cm}^{3} \mathrm{~min}^{-1}$ flow rate.

change in the recovery of Th(IV). The tolerances for alkali and alkaline earth elements using $20 \mu \mathrm{g}$ of $\mathrm{Th}(\mathrm{IV})$ were $100 \mu \mathrm{g}$ for sodium(I), $250 \mu \mathrm{g}$ for potassium(I) and magnesium(II), and $500 \mu \mathrm{g}$ for calcium(II). Iron(III), nickel(II), lanthanum(III), and uranium(VI) showed strong interferences as they were tolerated in the ratios $1: 1,1: 1,1$ : 1.5 , and $1: 1.5$ respectively. Certain elements like lead(II), yttrium(III), neodymium(III), samarium(III), and dysprosium(III) had good tolerances with tolerance ratios $1: 5$, $1: 7.5,1: 12.5,1: 5$, and $1: 5$, respectively. Various anions like $\mathrm{Cl}^{-}, \mathrm{NO}_{3}{ }^{-}, \mathrm{SO}_{4}{ }^{2-}$ showed high tolerance limits for Th(IV). Binary mixtures were proposed for separation of Th(IV) from other elements. The resulting separation factors $\left(\beta=D_{\mathrm{Th}}: D_{\mathrm{M}}\right)$ were good (Table 2). As the other element remained in the aqueous phase and was determined quantitatively.

\subsection{Batch mode}

\section{Sorption capacity of impregnated resin}

A $20.0 \mathrm{~cm}^{3}$ solution containing (1.0-10.0) $\mathrm{mg} \mathrm{Th}(\mathrm{IV})$ in $0.001 \mathrm{M} \mathrm{HNO}_{3}$ was shaken for a predetermined time of $20 \mathrm{~min}$. in a stoppered bottle on a mechanical shaker. After phase separation, Th(IV) was determined in the aqueous phase spectrophotometrically. The sorption capacity was defined as the maximum amount of $\mathrm{Th}(\mathrm{IV})$ adsorbed on the
Table 2. Separation of Th(IV) from binary mixtures (aqueous phase condition $=20 \mu \mathrm{g} \mathrm{Th}(\mathrm{IV})$ in $10.0 \mathrm{~cm}^{3}$ of $0.001 \mathrm{M} \mathrm{HNO}_{3}$, at $1.0 \mathrm{~cm}^{3} \mathrm{~min}^{-1}$ flow rate, elution condition $=10.0 \mathrm{~cm}^{3}$ of $4.0 \mathrm{M} \mathrm{HCl}$, at $0.6 \mathrm{~cm}^{3} \mathrm{~min}^{-1}$ flow rate).

\begin{tabular}{lrccc}
\hline $\begin{array}{l}\text { Metal } \\
\text { ion }\end{array}$ & $\begin{array}{c}\text { Amount } \\
\text { of metal } \\
\text { added } \\
(\mu \mathrm{g})\end{array}$ & $\begin{array}{c}\text { Metal un- } \\
\text { extracted } \\
(\%)^{ \pm a}\end{array}$ & $\begin{array}{c}\text { Recovery } \\
\text { of Th(IV) } \\
(\%)^{ \pm a}\end{array}$ & $\begin{array}{c}\text { Separation } \\
\text { factor }(\beta) \\
\beta=D_{\mathrm{Th}}: D_{\mathrm{M}}\end{array}$ \\
\hline $\mathrm{Na}(\mathrm{I})$ & 100 & $99.8 \pm 0.1$ & $98.9 \pm 0.2$ & $55.9 \times 10^{3}$ \\
$\mathrm{~K}(\mathrm{I})$ & 250 & $99.0 \pm 1.7$ & $99.0 \pm 0.2$ & $10.7 \times 10^{3}$ \\
$\mathrm{Ca}(\mathrm{II})$ & 500 & $99.8 \pm 0.2$ & $99.4 \pm 0.4$ & $71.2 \times 10^{3}$ \\
$\mathrm{Mg}(\mathrm{II})$ & 250 & $99.1 \pm 0.7$ & $99.2 \pm 0.2$ & $14.7 \times 10^{3}$ \\
$\mathrm{Fe}(\mathrm{III})$ & 20 & $87.9 \pm 2.0$ & $98.8 \pm 0.4$ & $11.9 \times 10^{2}$ \\
$\mathrm{Co}(\mathrm{II})$ & 100 & $98.9 \pm 0.1$ & $99.6 \pm 0.2$ & $22.7 \times 10^{3}$ \\
$\mathrm{Ni}(\mathrm{II})$ & 20 & $99.0 \pm 0.2$ & $99.0 \pm 0.2$ & $90.6 \times 10^{2}$ \\
$\mathrm{~Pb}(\mathrm{II})$ & 100 & $99.0 \pm 0.1$ & $99.4 \pm 0.3$ & $16.7 \times 10^{3}$ \\
$\mathrm{Y}(\mathrm{III})$ & 150 & $99.2 \pm 0.3$ & $99.1 \pm 0.3$ & $17.6 \times 10^{3}$ \\
$\mathrm{La}(\mathrm{III})$ & 30 & $98.5 \pm 0.2$ & $98.8 \pm 0.3$ & $94.0 \times 10^{2}$ \\
$\mathrm{Ce}(\mathrm{IV})$ & 60 & $98.7 \pm 0.3$ & $99.4 \pm 0.3$ & $10.4 \times 10^{3}$ \\
$\mathrm{Pr}(\mathrm{III})$ & 40 & $99.6 \pm 0.2$ & $99.2 \pm 0.2$ & $33.3 \times 10^{3}$ \\
$\mathrm{Nd}(\mathrm{III})$ & 250 & $99.0 \pm 0.2$ & $99.0 \pm 0.2$ & $18.4 \times 10^{3}$ \\
$\mathrm{Sm}(\mathrm{III})$ & 100 & $99.4 \pm 0.3$ & $99.2 \pm 0.2$ & $21.9 \times 10^{3}$ \\
$\mathrm{Gd}(\mathrm{III})$ & 40 & $99.7 \pm 0.1$ & $98.7 \pm 0.2$ & $44.4 \times 10^{3}$ \\
$\mathrm{Dy}(\mathrm{III})$ & 100 & $99.5 \pm 0.2$ & $99.3 \pm 0.2$ & $26.3 \times 10^{3}$ \\
$\mathrm{U}(\mathrm{VI})$ & 30 & $83.1 \pm 0.3$ & $99.3 \pm 0.2$ & $69.6 \times 10^{1}$ \\
\hline
\end{tabular}

a: $=\%$ R.S.D. $(N=3)$.

impregnated resin at equilibrium, under its optimum conditions for sorption. Amberlite XAD-2 resin impregnated with Cyanex 272 had a sorption capacity of $8.48 \mathrm{mmol} \mathrm{g}^{-1}$.

\section{Adsorption isotherms for $\mathrm{Th}(\mathrm{IV})$ on impregnated resin}

$100 \mathrm{mg}$ Amberlite XAD-2 impregnated with $100 \mathrm{mg}$ Cyanex 272 and $20.0 \mathrm{~cm}^{3}$ of $0.001 \mathrm{M} \mathrm{HNO}_{3}$ solutions containing (50-500) $\mathrm{mg} \mathrm{dm}^{-3}$ of Th(IV) were shaken in a stoppered bottle on a mechanical shaker for $20 \mathrm{~min}$. The modified support was filtered and the residual solution was analyzed for Th(IV) spectrophotometrically. The experimental data for adsorption isotherm was treated for Langmuir and Freundlich adsorption isotherm models. The rearranged Langmuir equation [19] is as follows:

$$
\frac{C_{\mathrm{e}}}{q_{\mathrm{e}}}=\frac{1}{q_{\mathrm{o}} b}+\frac{C_{\mathrm{e}}}{q_{\mathrm{o}}}
$$

$C_{\mathrm{e}}$ is the equilibrium concentration of Th(IV) $\left(\mathrm{mg} \mathrm{dm}^{-3}\right), q_{\mathrm{e}}$ is its amount adsorbed at equilibrium and $q_{\mathrm{o}}$ and $b$ are Lang- 


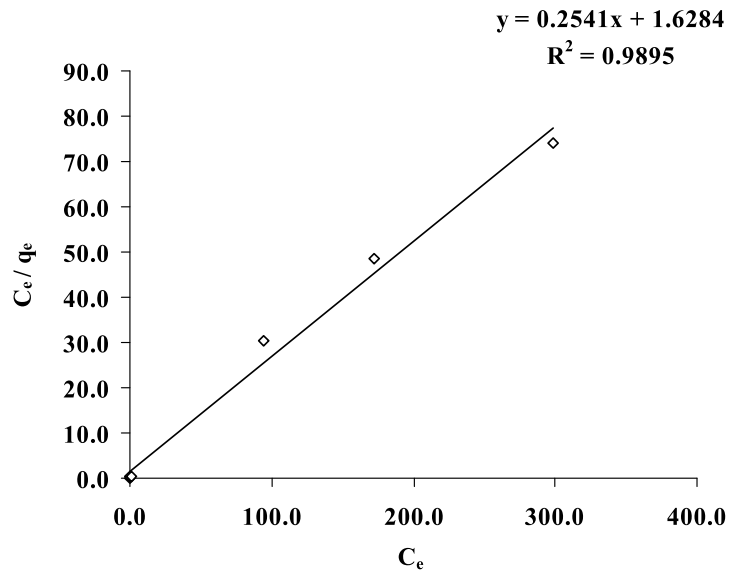

Fig. 3. Langmuir adsorption isotherm. Experimental condition: $100 \mathrm{mg}$ Amberlite XAD-2 impregnated with $100 \mathrm{mg}$ Cyanex272. Aqueous phase condition $=(50-500) \mathrm{mg} \mathrm{dm}^{-3} \mathrm{Th}(\mathrm{IV})$ in $20.0 \mathrm{~cm}^{3}$ of $0.001 \mathrm{M}$ $\mathrm{HNO}_{3}$, shaking time $=20 \mathrm{~min}$.

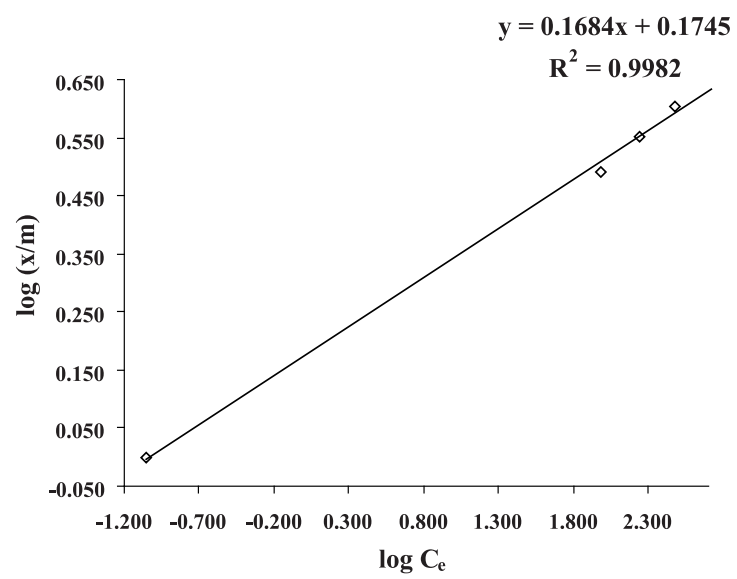

Fig. 4. Freundlich adsorption isotherm. Experimental condition: $100 \mathrm{mg}$ Amberlite XAD-2 impregnated with $100 \mathrm{mg}$ Cyanex272 aqueous phase condition $=(50-500) \mathrm{mg} \mathrm{dm}^{-3} \mathrm{Th}(\mathrm{IV})$ in $20.0 \mathrm{~cm}^{3}$ of $0.001 \mathrm{M} \mathrm{HNO}_{3}$, shaking time $=20 \mathrm{~min}$.

muir constants related to adsorption capacity and energy of adsorption, respectively.

While, Freundlich equation [19] is represented as follows:

$$
\log (x / m)=\log K_{\mathrm{f}}+\log C_{\mathrm{e}}(1 / n)
$$

$x / m$ is the amount of metal adsorbed per $100 \mathrm{mg}$ impregnated resin, $K_{\mathrm{f}}$ the Freundlich constant is the measure of adsorption capacity, and $1 / n$ is adsorption intensity. The plots of $C_{\mathrm{e}} / q_{\mathrm{e}} v s . C_{\mathrm{e}}$ and $\log (x / m) v s . \log C_{\mathrm{e}}$ indicated that the adsorption of Th(IV) on Cyanex272 impregnated on Amberlite XAD-2 resin obeyed Langmuir as well as Freundlich adsorption isotherm models (Figs. 3 and 4). The correlation coefficient $\left(R^{2}\right)$ for the linear regression fit of the Langmuir plot as well as Freundlich plot were 0.986 and 0.998 respectively while the vales for $q_{\mathrm{o}}, b, K_{\mathrm{f}}$, and n were $3.93,0.16$, 1.50 and 5.93 respectively.

\section{Precision and detection limit}

Th(IV) determination using the same column in six replicate determinations had a relative standard deviation (R.S.D.) of $0.8 \%$. The limit of detection (LOD) evaluated, as three
Table 3. Separation of Th(IV) from synthetic mixtures (aqueous phase condition $=20 \mu \mathrm{g}$ Th(IV) in $10.0 \mathrm{~cm}^{3}$ of $0.001 \mathrm{M} \mathrm{HNO}_{3}$, at $1.0 \mathrm{~cm}^{3} \mathrm{~min}^{-1}$ flow rate, elution condition $=10.0 \mathrm{~cm}^{3}$ of $4.0 \mathrm{M} \mathrm{HCl}$, at $0.6 \mathrm{~cm}^{3} \mathrm{~min}^{-1}$ flow rate).

\begin{tabular}{lc}
\hline Composition of synthetic mixture & $\begin{array}{c}\text { Recovery of } \\
\text { Th(IV) }(\%)^{ \pm a}\end{array}$ \\
\hline $\mathrm{Ca}(\mathrm{II}) ; 10 \mu \mathrm{g}, \mathrm{Pb}(\mathrm{IV}) ; 10 \mu \mathrm{g}, \mathrm{Th}(\mathrm{IV}) ; 10 \mu \mathrm{g}$ & $99.3 \pm 0.4$ \\
\hline $\mathrm{Ca}(\mathrm{II}) ; 2.5 \mu \mathrm{g}, \mathrm{Ce}(\mathrm{IV}) ; 12.5 \mu \mathrm{g}, \mathrm{Sm}(\mathrm{III}) ; 17.5 \mu \mathrm{g}$, & $98.6 \pm 0.1$ \\
$\mathrm{Gd}(\mathrm{III}) ; 17.5 \mu \mathrm{g}, \mathrm{Nd}(\mathrm{III}) ; 10.0 \mu \mathrm{g}, \mathrm{Th}(\mathrm{IV}) ; 20 \mu \mathrm{g}$ & \\
\hline $\mathrm{Ca}(\mathrm{II}) ; 20 \mu \mathrm{g}, \mathrm{La}(\mathrm{III}) ; 7.5 \mu \mathrm{g}, \mathrm{Ce}(\mathrm{IV}) ; 17.5 \mu \mathrm{g}$, & $98.8 \pm 0.4$ \\
$\mathrm{Nd}(\mathrm{III}) 5.0 \mu \mathrm{g}, \mathrm{Th}(\mathrm{IV}) ; 20 \mu \mathrm{g}$ & \\
\hline $\mathrm{Na}(\mathrm{I}) ; 10 \mu \mathrm{g}, \mathrm{Sr}(\mathrm{II}) ; 30 \mu \mathrm{g}, \mathrm{Th}(\mathrm{IV}) ; 20 \mu \mathrm{g}$ & $99.3 \pm 0.2$ \\
\hline $\mathrm{Ba}(\mathrm{II}) ; 95 \mu \mathrm{g}, \mathrm{K}(\mathrm{I}) ; 1.0 \mu \mathrm{g}, \mathrm{Na}(\mathrm{I}) ; 1.0 \mu \mathrm{g}$, & $99.1 \pm 0.3$ \\
$\mathrm{Sr}(\mathrm{II}) ; 5.0 \mu \mathrm{g}, \mathrm{Ca}(\mathrm{II}) ; 2.5 \mu \mathrm{g}, \mathrm{La}(\mathrm{III}) ; 22.5 \mu \mathrm{g}$, & \\
$\mathrm{Ce}(\mathrm{IV}) ; 10 \mu \mathrm{g}, \mathrm{Nd}(\mathrm{III}) ; 2.5 \mu \mathrm{g}, \mathrm{Th}(\mathrm{IV}) ; 20 \mu \mathrm{g}$ & \\
\hline $\mathrm{a}:=\%$ R.S.D. $(N=3)$. &
\end{tabular}

times the standard deviation of the blank signal [19] was $0.67 \mu \mathrm{g} \mathrm{dm}^{-3}$.

\section{Analytical applications}

\subsection{Separation of Th(IV) from synthetic mixtures}

The method developed was applied to separate and recover Th(IV) from synthetic mixtures containing elements commonly associated with it The recovery of Th(IV) was quantitative with a R.S.D. not more than $0.8 \%$ (Table 3). The other elements were not sorbed under the optimum conditions for sorption of Th(IV) and were quantitatively determined in the aqueous phase by FAAS or ICP-AES.

\subsection{Recovery of $T h(I V)$ from monazite sand}

The applicability of the method developed was checked using an aliquot of sample prepared as described in experimental section 2.5. The amount of Th(IV) detected in monazite sand was $114.98 \pm 0.28 \mathrm{mg} \mathrm{g}^{-1}$ as against $115.91 \mathrm{mg}$ present in it. This result using sample solution was cross-

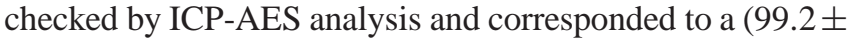
$0.3) \%$ recovery for $\mathrm{Th}(\mathrm{IV})$ and had R.S.D. within $0.8 \%$.

\section{Conclusion}

The separation and determination of Th(IV) using Amberlite XAD-2 resin impregnated with Cyanex 272 is a simple, selective, and specific method to isolate traces of Th(IV) from associated elements. The sorption capacity for Th(IV) was superior [4-8, 10, 12], reusability good and LOD low [4-10, 15] in comparison to other solid phase extraction methods. The method developed was successfully applied for recovery of Th(IV) from monazite sand.

\section{References}

1. Rao, T. P., Metilda, P., Gladis, J. M.: Preconcentration technique for uranium(VI) and thorium(IV) prior to analytical determination-an overview. Talanta 68, 1047 (2006). 
2. Metilda, P., Gladis, J. M., Rao, T. P.: Synthesis of malonic acidfunctionalized Amberlite XAD-4 and its use in solid phase extraction/preconcentrative separation of thorium(IV). Radiochim. Acta 92, 931 (2004).

3. Jain, V. K., Handa, A., Sait, S. S., Shrivastav, P., Agrawal, Y. K.: Preconcentration, separation and trace determination of lanthanum(III), cerium(III), thorium(IV) and uranium(VI) on polymer supported o-vanillinsemicarbazone. Anal. Chim. Acta 429, 237 (2001).

4. Prabhakaran, D., Subramanian, M. S.: Synthesis, characterization, and metal extractive behavior of functionalized AXAD-16 polymeric matrix using oxyacetone acetamide. Sep. Sci. Technol. 39, 941 (2004).

5. Raju, Ch. S. K., Srinivasan, S., Subramanian, M. S.: New multidentate ionselective AXAD-16-MOPPA polymer for the preconcentration and sequential separation of U(VI), Th(IV) from rare earth matrix. Sep. Sci. Technol. 40, 2213 (2005).

6. Maheswari, M. A., Subramanian, M. S.: New multidentate ionselective grafted polymer for preconcentration of lanthanides and actinides. Anal. Lett. 38, 1331 (2005).

7. Maheswari, M. A., Subramanian, M. S.: Selective enrichment of $\mathrm{U}(\mathrm{VI}), \mathrm{Th}(\mathrm{IV})$ and $\mathrm{La}(\mathrm{III})$ from high acidic streams using a new chelating ion-exchange polymeric matrix. Talanta 64, 202 (2004).

8. Seyhan, S., Merdivan, M., Demirel, N., Hosgoren, H.: Polymer supported 5,10,15,20-tetrakis(phenoxy acetic acid)porphyrin derivative for separation and preconcentration of $d$ - and $f$ electron metals. Microchim. Acta 161, 87 (2008).

9. Metilda, P., Gladis, J. M., Rao, T. P.: Catechol functionalized aminopropyl silica gel: synthesis, characterization and preconcentrative separation of uranium(VI) from thorium(IV). Radiochim. Acta 93, 219 (2005).
10. Demirel, N., Merdivan, M., Pirinccioglu, N., Hamamci, C.: Thorium(IV) and uranium(VI) sorption studies on octacarboxymethyl-C-methylcalix[4]resorcinarene impregnated on a polymeric support. Anal. Chim. Acta 485, 213 (2003).

11. Preetha, C. R., Gladis, J. M., Rao, T. P.: Solid phase extractive preconcentration of thorium onto 5,7-dichloroquinoline-8-ol modified benzophenone. Talanta 58, 701 (2002).

12. Seyhan, S., Merdivan, M., Demirel, N.: Use of o-phenylene dioxydiacetic acid impregnated in amberlite XAD resin for separation and preconcentration of uranium(VI) and thorium(IV). J. Hazard. Mater. 152, 79 (2008).

13. Chen, J. H., Kao, Y. Y., Lin, C. H.: Selective separation of vanadium from molybdenum using $\mathrm{D}_{2}$ EHPA-immobilized Amberlite XAD-4 resin. Sep. Sci. Technol. 38, 3827 (2003).

14. Chah, S., Kim, J. S., Yi, J.: Separation of zinc ions from aqueous solutions using modified silica impregnated with Cyanex272. Sep. Sci. Technol. 37, 701 (2002).

15. Karve, M., Rajgor, R. V.: Amberlite XAD-2 impregnated with Cyanex302 for separation of traces of thorium(IV). Sep. Sci. Technol. 42, 2255 (2007).

16. Welcher, F. J.: The Analytical Uses of Ethylenediaminetetraaceticacid. D. Van Nostrand Co. Inc., New Jersey (1978), p. 181.

17. Snell, F. D.: Photometric and Fluorometric Methods of Analysis of Metals. John Wiley and Sons, New York (1978), p. 2167.

18. Scott, W. W.: Standard Methods of Chemical Analysis. $5^{\text {th }}$ Edn., Vol. 1 (Furman, N. H., ed.) D. Van Nostrand Co. Inc., New Jersey (1939), p. 948.

19. Metilda, P., Sanghamitra, K., Gladis, J. M., Naidu, G. R. K., Rao, T. P.: Amberlite XAD-4 functionalized with succinic acid for the solid phase extractive preconcentration and separation of uranium(VI). Talanta 65, 192 (2005). 